\title{
Revisiting the Conceptualisation of Politeness in English and Japanese
}

Michael Haugh

\begin{abstract}
The issue of what in fact constitutes politeness remains a source of considerable debate amongst researchers. There is mounting evidence that although there may be common underlying elements, politeness is conceptualised differently across cultures. A comparison of the notions of politeness in English and teinei, reigi tadashii and keii hyoogen in Japanese indicates that these respective terms encompass somewhat different conceptual ranges. Politeness in English refers to showing consideration for others, and demonstrating a polished self-presentation. In Japanese, on the other hand, it encompasses showing respect (with a strong nuance of vertical respect involved) and consideration towards the position and quality of character of others, and modesty about oneself. While politeness in both English and Japanese involves showing one thinks well of others (other-oriented politeness) and showing one does not think too highly of oneself (self-oriented politeness), differences in the underlying conceptualisation of politeness give rise to different ways of expressing politeness. It is thus difficult to maintain the assumption that politeness can be defined in the same way across different cultures, although this does not necessarily preclude the identification of common elements of politeness across cultures.
\end{abstract}

\section{Introduction}

Politeness is an important concept in everyday interactions, but it has also become increasingly popular as a focus of study in pragmatics and other disciplines in the past thirty years. The academic study of politeness, however, has led to the increasing dichotomisation of the concept between the intuitive understanding of politeness of ordinary speakers, and technical conceptualisations of politeness developed by researchers. Watts, Ide and Ehlich (1992) propose that these two perspectives have diverged to such an extent that they need to be clearly differentiated into commonsense or first-order concepts, and theoretical or second-order concepts of politeness.

First-order politeness involves the '...various ways in which polite behaviour is perceived and talked about by members of sociocultural groups...' (ibid: 3). In other words, first-order politeness, according to Watts et al. (1992), is a 
commonsense or lay conceptualisation of politeness. However, while Watts et al. (1992) initially defined first-order politeness as lay conceptualisations of politeness, Eelen $(1999,2001)$ argues that it is not just a concept talked about by people, but is also a phenomenon inextricably linked to their behaviour. First-order politeness is thus intuitively a mixture of politeness as a lay concept of which speakers are consciously aware, and politeness-in-action, which is implicit only in discursive practices, and thus at times people are not necessarily consciously aware of it (Eelen, 2001; Ehlich, 1992). Second-order politeness, on the other hand, is a theoretical construct, a term within a theory of social behaviour and language use. In some cases, second-order politeness is labeled with different terms, such as "rapport management" (Spencer-Oatey, 2000), "politic behaviour" (Watts, 1989, 1992), "language diplomacy" (Obana and Tomoda, 1996) and so on, in an attempt to differentiate these technical notions from lay conceptualisations.

The distinction between first-order and second-order politeness also echoes fundamental differences in the assumptions underlying research on politeness. Research based on first-order notions of politeness proceeds on the assumption that differences in politeness forms and strategies reflect divergences in the ways in which politeness is conceptualised in different cultures. In contrast, it is often assumed in research based on second-order notions of politeness that politeness is conceptualised in the same way across cultures, and that differences in politeness forms and strategies are simply a reflection of divergences in the structures that constitute different languages and the norms governing the usage of those structures.

The distinction made between first-order politeness and second-order politeness, while not always easy to rigorously maintain, draws attention to the central issue of what in fact constitutes politeness. There is mounting evidence that, although there may be common underlying elements, politeness is conceptualised differently across cultures (Almursy and Wilson, 2001; Ide, 1989; Janney and Arndt, 1993; Lee-Wong, 2002; Matsumoto, 1989; Nwoye, 1989). In this paper then, the way in which politeness is conceptualised in English and Japanese is compared and contrasted, to clarify what is common to, as well as what differs between the notions of politeness in these two languages.

This investigation of the concepts of politeness in English and Japanese rests on the assumption that the study of politeness should ultimately be to do with how ordinary speakers think, and show how they think through their behaviour, about 
politeness. One reason for this is that politeness is an important aspect of many social interactions, and since politeness is an integral part of our social lives, it is not something that can be studied without taking into account the perspective of actual interactants. Another reason is that the results of this kind of research may be more readily utilised in teaching second-language learners pragmatic aspects of the language in question, as key similarities and differences can be highlighted. In relation to pragmatic research, a further reason is that in interpersonal and intercultural communication, one may observe that conflicts can arise from the way in which politeness is exploited by certain speakers (Watts, 2002), or because different interactants have varying perspectives on politeness; and to analyse these kinds of situations, one must first consider how the speakers themselves conceptualise politeness. The notion of politeness is indeed complex, but this does not mean the pursuit of a definitive characterisation of it should be abandoned.

In the next section of this paper, the way in which politeness is conceptualised in English is discussed, before analysing the equivalent notions in Japanese. The way in which these conceptualisations can give rise to different politeness strategies is then discussed. It is also argued in this section that while there may be fundamental differences, there are also underlying elements common to both the English and Japanese conceptualisations of politeness; namely, that politeness in English and Japanese may arise from showing what one thinks of oneself (self-oriented politeness), as well as from showing what one thinks of others (other-oriented politeness). In conclusion, the implications of this analysis for further research on politeness are considered.

\section{Conceptualisations of politeness in English}

The English terms politeness (or polite) are broadly defined as 'having or showing behaviour that is respectful and considerate of other people' in The New Oxford Dictionary of English (Pearsall, 1998: 1435). These terms date back to the fifteenth century and were derived from Late Medieval Latin politus ('to smooth', 'polish'), but came into particular prominence in late $17^{\text {th }}$ and early $18^{\text {th }}$ century England (Klein, 1994: 3). Close analysis of the term polite(ness) as it is defined in The Oxford English Dictionary reveals at least two different but overlapping senses in which it has been used (Simpson and Weiner, 1989, Vol. 12: 31).

Polite (adj)

1. Of persons (a) in respect of some art or scholarship, (b) in respect of general 
culture: Polished, refined, civilized, cultivated, cultured, well-bred, modish. One of the politest wits in the Kingdome for the Law (1629); Whatever the polite and learned may think (1840).

2. Of refined manners; esp. showing courteous consideration for others; courteous, mannerly, urbane. [He] perceives the wise are polite all the world over, but that fools are polite only at home (1762); He sent me the following polite acknowledgment of his having received the work (1831).

The first sense of polite(ness) refers to politeness as a means of showing one's social class: that is, one is of a 'higher class' than others. In other words, showing what one thinks of oneself. Thus, while people tend to focus mainly on other-oriented (politeness) behaviour when thinking about politeness, examination of the roots of the notion of politeness indicate that the lay concept does in fact refer to both self- and other-oriented (politeness) behaviour.

The second sense of polite(ness) refers to showing 'good manners' or 'courtesy', which is related to showing what one thinks of others. The term courtesy (or courteous) is borrowed from French courtoisie, which has its origins in court life in medieval Europe, where 'to set an example of good behaviour was incumbent on the courteous man, be he king or lowly squire' (Wildeblood and Brinson, 1965: 44). However, it later spread into wider society, as the medieval doctrine of one's 'place' being fixed in an hierarchical society gradually gave way from the Renaissance era onwards to a 'polite world', which was open to those in the middle class who were able to rise above others through wealth or success (ibid: 46-67). It appears, then, that both the first and second senses of politeness have their origins in the upper echelons of society using certain behaviours, which they termed polite(ness), to distinguish themselves from those lower in the social hierarchy.

In the past century, however, politeness has come to be used in a more egalitarian manner, losing to some extent its nuance of marking the upper classes. ${ }^{1}$ In modern English, the terms 'polished' and 'refined' are more often a matter of displaying modesty than showing one is of higher class than others. This transformation into a more egalitarian notion is reflected in the various definitions of politeness that have recently emerged in pragmatics. These definitions fall into essentially four groups: politeness as 'behaviour avoiding conflict and promoting smooth communication', politeness as 'socially appropriate behaviour', politeness as 'consideration for the feelings of others', and politeness as an 'evaluation of the speaker's behaviour by the addressee as polite'. 
One of the most common conceptualisations of politeness in pragmatic research is the definition of politeness as 'conflict avoidance' (Brown and Levinson, 1987: 1; Lakoff, 1975: 64; Leech, 1983; 1999: 1; Marquez-Reiter, 2000: 5). Closely related to this is the notion of politeness as 'behaviour which promotes smooth communication between interlocutors' (Ide, 1989: 225; 1993: 7; Usami, 2001: 10; 2002: 4). The definition of politeness as a means to avoid conflict and promote smooth communication is the consensus point for many studies of politeness at present. It seems to be closely related to the original sense of politeness where one makes things run smoothly, in particular, relationships between people, and thus serves to focus attention on one of the main purposes of politeness (that is, promoting smooth interpersonal communication).

An alternative conceptualisation of politeness that has emerged is the definition of politeness as 'appropriate' or 'adequate' behaviour according to social norms (Braun and Schubert, 1988: 49-50; Meier, 1995a: 387; 1995b: 351; Sifianou, 1992: 86). Fraser (1990; see also Fraser and Nolen, 1981), in a similar vein, has proposed that '... being polite constitutes operating within the then-current terms and conditions of the conversational contract...' (1990: 233). The conversational contract is essentially an alternative conceptualisation of norms regarding what interlocutors can expect of each other in conversations. Some of these norms are imposed through conventions, while others are negotiable in the course of interaction. This approach appears to be more closely related to the original sense of politeness as being 'polished', in that one's behaviour is appropriate (that is, polished) to each situation. Politeness conceptualised in this way serves to focus attention on the inherently normative or conventional nature of politeness.

A third broad approach to the concept of politeness is the definition of politeness as 'consideration for others' feelings as to how they should be treated in interactions' (Brown, 2001; Hill, Ide, Ikuta, Kawasaki, Ogino, 1986: 349; Ide, 1991: 63, Sifianou, 1992: 83). Brown (2001: 11620) talks about 'concern for interactors' social status and their social relationship', Ide (1991: 63) mentions establishing a 'distance of mutual comfort', while Sifianou (1992: 83) qualifies it in terms of social norms. This conceptualisation is essentially derived from the general definition of politeness - mentioned at the beginning of this section - as respectful or considerate behaviour. In other words, this definition is closest to how politeness is commonly described by ordinary speakers of English.

In a fourth approach, that has only just recently emerged, politeness is defined as an evaluation of the speaker's behaviour by the addressee as polite (Eelen, 1999, 
163; 2001: 248-249; Mills, 2003; Terkourafi, 2001: 127). In this approach to politeness, it is the addressee's evaluation of the speaker's behaviour, rather than the speaker's behaviour or intention itself, which proves crucial as to whether or not politeness arises. This 'reception-based' approach thus differs in its perspective from the three other conceptualisations of politeness in pragmatics, which are 'production-based' notions. However, while the idea that evaluations of speakers' behaviour by addressees are crucial to politeness is indeed important, none of these 'reception-based' notions indicate what politeness itself might be. In other words, they characterise politeness as something where an addressee thinks a speaker is being polite, but they do not explain why the addressee will consider the speaker to be polite.

From this brief review of various definitions of politeness it appears that politeness in English involves being both well-mannered in one's own demeanour (that is, polished or appropriate behaviour), and showing consideration to the feelings or position of others, thereby ensuring better relationships between people (that is, smooth communication). It can only arise in interactions, since it always involves evaluations, which are partially based on norms or conventions, of the speaker's behaviour by the addressee or other on-lookers.

This analysis is consistent with previous research about English speakers' conceptualisations of politeness. For example, in a written survey of 27 British speakers of English, Sifianou (1992) found that politeness was regarded as '...the consideration of other people's feelings by conforming to social norms and expectations...' (p.88). Obana and Tomoda (1994) found in interviews with Australian speakers of English that politeness was associated with terms such as kind, friendly, considerate, humble, respect and so on, with similar results gained from a survey of American speakers of English (Ide, Hill, Carnes, Ogino and Kawasaki, 1992; Ide and Yoshida, 1999).

Politeness in English is thus essentially a matter of being perceived as well-mannered in one's demeanour, and showing consideration and respect towards the feelings of others in line with social expectations. In the following section, the ways in which the notion of politeness in Japanese differs from that in English are discussed.

\section{Conceptualising Japanese politeness}

The term politeness is invariably translated as teinei or reigi tadashii indicating that these are the nearest equivalents of the English concept in Japanese. Teinei 
is defined as follows in the Koojien dictionary (Shinmura, 1991: 1751). ${ }^{2}$

Teinei

1. Teatsuku reigi tadashii koto.

deeply etiquette correct thing

2. Chuui-bukaku kokoro ga yukitodoku koto. attention-deeply heart Nom fully reach thing

(1. To be warm (sincere) and correct in one's manners.

2. To be extra careful in what one does. $)^{3}$

The first sense of teinei is to be warm-hearted (or kind) and correct in one's manners (reigi), and it is in this sense that it is used as a translation of the term politeness. According to the Daikangorin dictionary (Kamada and Komeyama, 1992), the aspect of being warm-hearted (teatsui) is related to the first character tei (丁) (p.8), while being kind (shinsetsu) and elaborate in one's courtesy (nengoro) is related to the second character nei (寧) (p.346). Nei originally meant to offer flowers to supplicate to the gods, thereby finding peace in one's heart. This feeling of being at ease was metaphorically extended to cover feelings of 'kindness' and 'courtesy'. Politeness in Japanese, in the sense of teinei, thus involves showing 'warmth', 'kindness' and 'courtesy', but it is also closely related to the notion of reigi.

The term reigi tadashii is more complex as it is a set collocation of the terms reigi and tadashii. Reigi is denser in its meaning, while the latter simply refers to being 'correct'. The former is defined as follows in the Kojien dictionary (Shinmura, 1991: 2715).

Reigi

1. Keii o arawasu sahoo. Rei no sahoo.

respect Acc express manners ritual of manners

2. Sharei, hooshuu.

gratitude money reward

(1. Manners/etiquette which express 'vertical respect' or propriety.

2. A reward/fee expressing thanks.)

The first sense of reigi is a matter of 'manners' or 'etiquette' (sahoo) which express 'vertical respect' (keii) or 'propriety' (rei). The second sense refers to a specific reward or fee given to express gratitude, thus it is reigi in its first sense which is equivalent, at least to some extent, to the term politeness.

The character rei (礼) is further defined as follows in the Koojien dictionary (Shinmura, 1991: 2714): 
Rei

1. Shakai no chitsujo o tamotsu tame no seikatsu kihan no sooshoo.

society of order Acc protect in order of life standard of general term

Gishiki, sahoo, seido, bunbutsu nado o fukumi, jukyoo dewa ceremony etiquette system civilisation et cetera Acc include Confucianism in mottomo juuyoona dootokuteki gainen toshite 'Raiki' nado ni toku. most important virtuous concept as 'Book of Rituals' et cetera in expound 2. Keii o mot-ta furumai. respect Acc have-Past behaviour

3. Uyamat-te haisuru koto. Ojigi. worship-Conj pray thing bow

4. Shai o arawasu koto. Mata, sono tameni okuru kinpin. gratitude Acc show thing also that in order send money/articles

5. Kumotsu. offering

(1. A general term for standards in the way one lives that maintain social order. It is expounded as the most important virtue in Confucianism (from The Book of Rituals), and includes ceremony, etiquette, systems and civilisation.

2. Respectful behaviour.

3. To worship and pray. To bow.

4. To show gratitude. Or gifts that express gratitude.

5. An offering.)

From the definition of the first sense of rei ('propriety') we can see that it was profoundly influenced by Confucian thinking about the concept of rei; and while Confucius did not entirely neglect more horizontal-type relationships in his discussions of rei, he mainly focused upon vertical/upward-looking relationships. For example, in the Filial Piety Sutra Confucius is quoted as saying:

'...Propriety is simply the expression of respect. Children will be happy if they respect their parents. Younger brothers and sisters will become happy if they respect their elder brother and sisters. Ministers will gain happiness if they respect their king...' (Chapter 12, Filial Piety Sutra: see Lau (1995) No.17, p.3 for original quote)

Rei is also closely associated with expressing keii, which as is discussed later, is associated with a vertical or upward-looking type of respect. Moreover, the first character, rei (礼) ('propriety') originally means to make an offering to the gods and pray for good fortune (Kamada and Komeyama, 1992: 1017), which also 
indicates a distinctly 'upward-looking' nuance inherent to the notion of rei. In other words, while respect (in English) is generally conceived of as mutual, rei involves primarily vertical (that is, one-way) respect.

The fact that reigi tadashii also involves a highly normative aspect can be seen from an analysis of the meaning of the character gi (儀), which is defined as follows in the Koojien dictionary (Shinmura, 1991: 599):

Gi

1. Shintai doosa no ue de tehon to su-beki mono. Hoosoku: girei, gyoogi behaviour manner of on at model as do-Imp thing rules courtesy manners

2. Sahoo ni shitagat-te shintai suru koto. Reishiki etiquette to follow-Te behaviour do thing ceremonial rituals kekkon no gi, gishiki, soogi wedding of ceremony ritual funeral ceremony

3. Katadoru koto. Mokei. (chikyuugi) imitate thing model globe

(1. A model one should follow in one's behaviour and actions. Rules such as courtesy or manners.

2. To behave according to etiquette. Ceremonal rituals such as wedding ceremonies, ceremonial rituals, funerals).

3. To imitate/make in the shape of something. Models such as globes.)

The first two senses of $g i$ relate to one's behaviour being in line with a 'good model' (tehon), that is, 'manners or etiquette' (sahoo). In other words, it involves behaviour that is in accordance with particular social norms. This follows from the fact that $g i$ (儀) is composed of 'person' (人) and 'righteous' (義), a righteous person being someone who can follow the 'way of propriety' (reihoo) (Kamada and Komeyama, 1992: 107).

The two key concepts associated with reigi are thus keii ('vertical respect') and sahoo ('manners and customs'). Sahoo is further defined as follows (Shinmura, 1991: 1048):

Sahoo

Kikyo, doosa no tadashii hooshiki.

life actions of correct formula

(Correct formula [ways] for actions and daily life)

From the meaning of sahoo which is important both to the definition of reigi, and to the meaning of tadashii ('correct'), which forms part of the overall collocation reigi tadashii, the normative character of the concept of reigi tadashii becomes 
more apparent. Reigi tadashii is about being 'correct' according to some kind of standard, implicitly understood to be constituted by social norms.

The notion of keii also involves a complex meaning. Keii itself means to show a feeling that is 'respectful' (ibid: 782). An analysis of the character kei (敬) indicates the nature of this 'respect'. According to the Daikangorin dictionary (Kamada and Komeyama, 1992: 622), keii incorporates the meanings of tattobu ('show reverence') and tsutsushimu ('be discreet' or 'refrain (from)'), since the original meaning of the character is to bend down and make an offering before the gods (ibid: 622). The things that are 'revered' (tattobu) include high 'social position' (mibun) or rank (chii), and others' 'quality of character' (jinkaku) (Kamada and Komeyama, 1992: 403; Shinmura, 1991: 1528, 1597). ${ }^{4}$ This kind of respect is thus upward-looking, a conclusion further evidenced by the origin of the character tattobu, where it means to hold up a container (Kamada and Komeyama, 1992: 403). The concept of 'discretion' or 'refrain' (tsutsushimu, 慎 屯), which is originally derived from the meaning of having a 'true' (shin, 真) 'heart' (kokoro, 心), is associated with 'being in awe' (uyauyashii) and 'modesty' (hikaeme) (ibid: 546). In other words, modesty or humility is also an important dimension of the notion of reigi. The way in which humility is valued can be traced back to ancient philosophers in China such as Confucius and Laozi. For example, in the Way of Life (Dao de Jing), Laozi is quoted as saying:

'Therefore the sage holds in his embrace the one thing (of humility), and manifests it to the world. He is free from self-display, and therefore he shines; from self-assertion, and therefore he is distinguished; from self-boasting, and therefore his merit is acknowledged; from self-complacency, and therefore he gains superiority' (Chapter 22, Dao De Jing: from translation by Legge, 1891: 65)

In other words, one may show one's quality of character through modesty or humility.

A word-map of this analysis of the concepts of teinei and reigi tadashii and related terms is presented in Figure One below. The key notions associated with politeness in Japanese are represented in this figure. The single-headed arrows indicate that the latter term is conceptually derivative of the term preceding it, while the double-headed arrow indicates that both terms are mutually interdependent. 


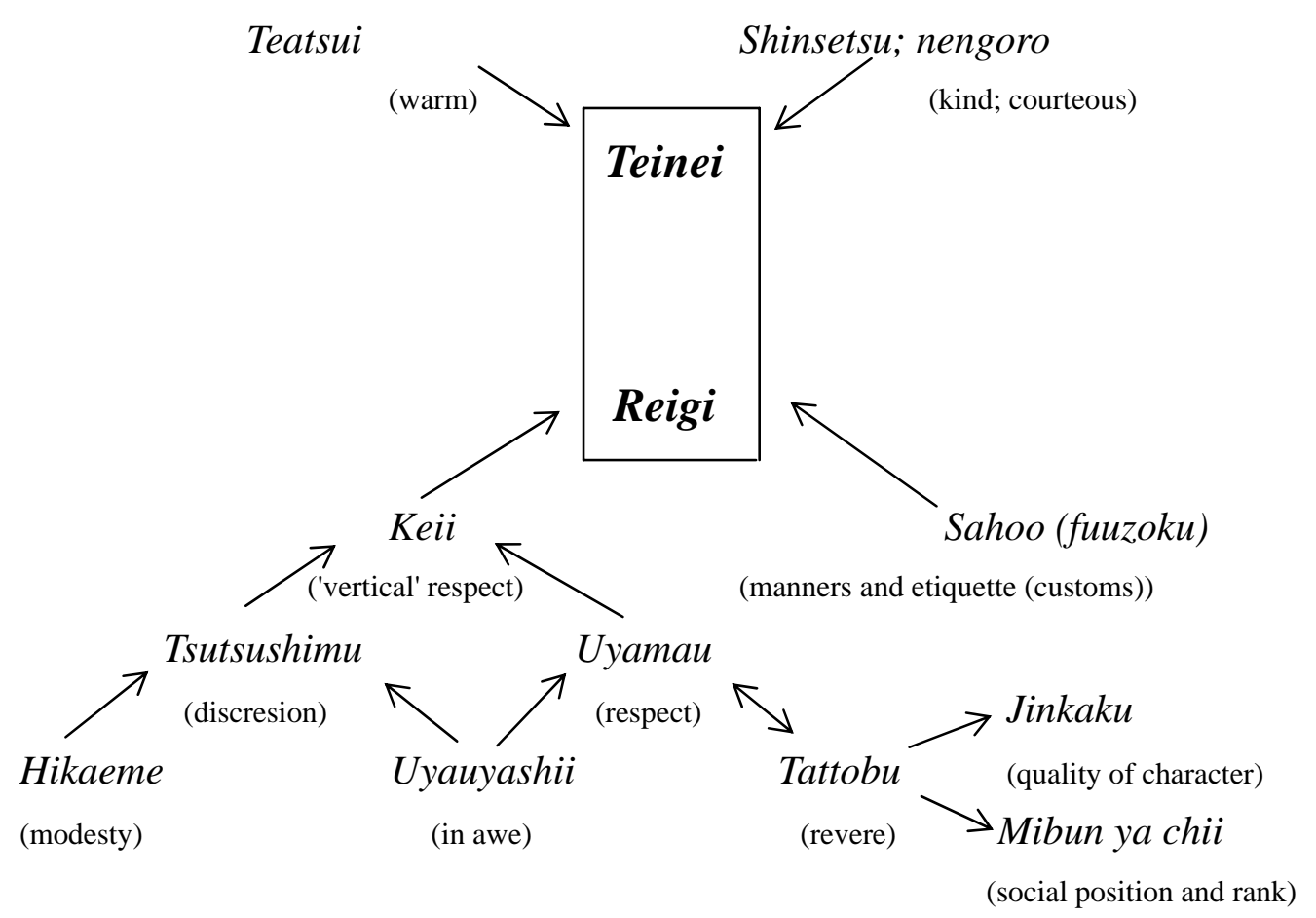

Figure One: Word map of politeness and related terms in Japanese

From the analysis of the concept of reigi tadashii, it appears that reigi tadashii is behaviour which shows 'upward' respect (keii) of the social position (mibun), rank (chii), quality of character (jinkaku) of others, and shows modesty (hikaeme) about oneself, in accordance with social norms (sahoo). Teinei, on the other hand, refers to showing warmth (teatsui), kindness (shinsetsu), and courtesy (nengoro) towards others. The concepts of reigi tadashii and teinei are thus not equivalent, although they are both used as translations of the English term politeness.

This analysis is consistent, at least in part, with previous research about Japanese speakers' conceptualisations of teinei and reigi tadashii. Ide et al.'s (1992) study of concepts which correlate with the notion of teinei found that it was closely associated with keii ('respect'), kanji yoi ('feeling good'), tekisetsu(sa) ('appropriateness'), omoiyari ('considerateness', 'kindness') (see also Ide and Yoshida, 1999), while in interviews with Japanese speakers, Obana and Tomoda (1994) found the terms were associated with knowing where one stands in social interactions (wakimae or 'discernment') and keigo (honorifics), which both involve 'upward' respect (that is, showing respect towards others of higher rank or status than oneself, and modesty about oneself), as well as horizontal distance. Obana 
(2000: 206) goes on to argue that Japanese often associate politeness with keigo (honorifics). She claims that this means that politeness is conceptualised by Japanese as means of setting barriers (according to social norms), both vertically and horizontally. Interestingly, the nuance of horizontal distance is not encompassed by dictionary definitions of the concepts of teinei and reigi tadashii, while the nuance of 'kindness' in teinei are not reflected in the responses of Japanese interviewed in Obana and Tomoda's (1994) study.

The use of the term keii hyoogen as a more appropriate equivalent than teinei or reigi tadashii to the English notion of politeness, both in academia and in everyday discourse, has recently been proposed at the meeting of the National Language Council (Ide, 2001). It is defined as follows:

'...Keii hyoogen means to consider (hairyo) the interlocutor and their position and use linguistic expressions appropriately, based on a feeling of mutual respect (sonchoo) in communication. It involves respecting that interlocutor's individual character (jinkaku) and position relative to others (tachiba), and choosing appropriate expressions from a range of honorifics (keigo) and a variety of other expressions...' (ibid: 5-6)

The concept of keii hyoogen, defined in this manner, has similarities to the lay concepts of teinei and reigi tadashii. However, it shifts the focus away from a concern for social position (mibun) or social status (chii), to less hierarchial dimensions, namely the interlocutors' 'individual character' (jinkaku) or their 'position relative to others' (tachiba). The use of the notions of 'mutual respect' (soogo sonchoo) and 'consideration for others' (hairyo) also emphasises the less hierarchial nature of this conceptualisation of politeness in Japanese. Nevertheless, the use of the term keii ensures that those notions encompassed by the traditional terms teinei and reigi tadashii, such as 'upward' respect, dignity, modesty, social position/rank and so on, remain part of this conceptualisation.

The term keii hyoogen itself is potentially controversial, since keii has connotations of 'upward' respect, rather than the more egalitarian or mutual respect referred to in its definition. In this sense then, the cover term keii hyoogen (connotating 'upward' respect) is not entirely consistent with how it is defined (that is, involving 'mutual' respect). But no matter how this issue is resolved, keii hyoogen is not synonymous with politeness as it is conceptualised in English, since the former involves 'quality of character' (jinkaku) and 'one's position relative to others' (tachiba) in contrast to the latter which does not. It is also worth noting that keii hyoogen is meant to encompass not only linguistic 
forms such as honorifics, but also the use of other expressions and strategies (ibid: 6 ), in spite of the fact this is not clear from the use of hyoogen, which usually only refers to linguistic expressions.

In this section, the notions of teinei (used to evaluate linguistic acts or people), reigi tadashii (used to evaluate people), and keii hyoogen (used to identify politeness phenomena) were analysed in order to understand how politeness is conceptualised in Japanese. Common elements observed amongst these three notions were used to clarify how politeness in Japanese is conceptualised. Teinei refers to showing warmth and kindness to others, while reigi tadashii involves showing 'upward' respect towards the social position, status and quality of character of others, and modesty about oneself, in line with social norms. Keii hyoogen overlaps with the concept of teinei, in that it involves showing consideration towards others, and with the notion of reigi tadashii, in that it encompasses showing respect towards the individual character and position of others, although this respect is less 'upwardly' focused. The intuitive conceptualisation of politeness in Japanese thus appears to involve showing respect (keii, sonchoo) and consideration (hairyo) towards the individual character (jinkaku) and (social) position (tachiba) of others, and modesty (hikaeme) about oneself, in line with social norms. This respect may be both 'upward' in orientation, as well as being more mutual in nature.

A comparison of the notions of politeness in English and teinei, reigi tadashii and keii hyoogen in Japanese indicates that these respective terms encompass somewhat different conceptual ranges. Politeness in English refers to showing consideration for others, and demonstrating a polished self-presentation. In Japanese, on the other hand, it encompasses showing respect (with a strong nuance of vertical respect involved) and consideration towards the position and quality of character of others, and modesty about oneself. In this sense, politeness in Japanese occupies a slightly narrower conceptual range than the English notion of politeness, as well highlighting different aspects (such as 'vertical' respect or one's 'position').

Manifestations of politeness in English and Japanese: other-oriented versus self-oriented politeness

In the previous two sections it emerged that politeness in English and Japanese is related both to our concern about what one shows one thinks of oneself in front of others ('self-oriented politeness'), and our concern for what others show they think 
of us ('other-oriented politeness'). ${ }^{5}$ In this section, the notions of 'self-oriented politeness' and 'other-oriented politeness' are introduced to illustrate the ways in which differences in the conceptualisation of politeness across cultures are manifested in English and Japanese.

Other-oriented politeness arises when one thinks others show they think well of oneself. This can be represented in the following manner, where A is the speaker, $\mathrm{B}$ is the addressee, and ' $\mathrm{U}$ ' is the speaker's utterance (including his or her manner of saying it) (see Haugh and Hinze (2003) for a more in-depth discussion of this approach).

Other-oriented Politeness arises when:

A says 'U'

'U' shows [A thinks well of B] or [A does not think badly of B]

'U' shows A thinks the same or better of $B$ than what A should show A thinks of B

$B$ thinks [A thinks well of B] or [A does not think badly of $B$ ] because of this For example, I might compliment a friend on her new shoes (A says 'U'), and thereby show that I approve of my friend ('U' shows A thinks well of B). Politeness arises when upon hearing the compliment my friend thinks I approve of her (B thinks A thinks well of B because of this), and this compliment is the same as or better than she expects ('U' shows A thinks the same or better of $B$ than what A should show A thinks of B). In general, other-oriented politeness in Japanese, involves showing vertically-oriented respect and consideration towards the quality of character and social position of others, while in English it is related to showing consideration towards the feelings of others, as can be seen in the following examples.

In the following conversation between two Japanese meeting for the first time, other-oriented politeness arises from the use of 'polite forms' which show respect towards the addressee's social position. ${ }^{6}$

(1) Kitagawa: Jaa, hajimemashite. Kitagawa to mooshi-masu.

um first time to meet Kitagawa Quot say(Hon)-Pol

(Um, how do you do? My name is Kitagawa)

Nakane: Aa, hajimemashite, anoo, Nakane to ii-masu.

ah first time to meet um Nakane Quot call-Pol

Paatii wa o-suki desu ka?

party Top Hon-like Cop(Pol) Q

(Ah, how do you do? Um, my name is Nakane. Do you like parties?) 
Kitagawa: Paatii desu ka? (laughs)

party Cop(Pol) Q

Paatii wa hotondo de-ta koto ga ari-masen.

party Top most go-Past thing Nom exist-Neg(Pol)

(Parties? (laughter) I haven't been to many parties at all)

Nakane: $<A^{\prime}$ soo desu $k a>$

oh so Cop(Pol) Q

(Oh, is that so?)

Kitagawa: $<$ Moo $>$ kekkonshiki no hirooen kurai desu.

well wedding of reception about $\mathrm{Cop}(\mathrm{Pol})$

(Well, my wedding reception is about all)

Nakane: A' soo desu $k a$.

oh so $\operatorname{Cop}(\mathrm{Pol}) \mathrm{Q}$

(Oh, is that so?) (adapted from Usami, 2002: 126)

In this conversation both Kitagawa and Nakane use the 'polite forms' of verbs at the end of all their utterances (e.g. desu, iimasu, arimasen etc.), as illustrated in this short excerpt. These 'polite forms' give rise to politeness, because they show that the speaker respects the social position of the addressee as someone with whom they are not familiar/intimate (' $\mathrm{U}$ ' shows A thinks well of $\mathrm{B}$ ), and this is expected in this situation where the interactants are meeting for the first time ('U' shows A thinks the same of B as what A should show A thinks of B). The 'super-polite form' of 'to call' (mooshimasu) in Kitagawa's first utterance shows greater respect to the social position of the addressee than the 'polite form' of 'to call' (iimasu) in Nakane's response, so it gives rise to a greater degree of politeness.

In a similar situation in English, however, politeness is manifested in other ways, as illustrated in the next example. The two interactants, who are meeting for the first time, were previously talking with some doctoral students (the symbols $<$ and $>$ indicate overlapping speech).

(2) Elizabeth: I'm Elizabeth

Irene: Elizabeth. I'm Irene.

Elizabeth: Irene. Are you a $\mathrm{PhD}$ student as well?

Irene: No, I'm, I'm just an "outsider", no I'm a <school teacher>

Elizabeth: <you're an outsider?> (laughter)

Irene: I'm a school teacher

Elizabeth: It gets like that though, when <you're> 
Irene: <yes>

Elizabeth: in this sort of community doesn't it?

Irene: It's a bit incestuous is it?

Elizabeth: (laughter), oh I don't < know $>$

Irene: <(laughter)>

Elizabeth: I'm an undergraduate

Irene: Yeah

Elizabeth: So, yeah, I'm not, not into that sort of, um, what do they call it?,

postgraduate stuff, yeah, which probably is, might be a bit incestuous, yeah. ${ }^{7}$

In this conversation Elizabeth and Irene do not show respect as such towards each other as newly acquainted people. Instead, they start to establish a kind of common bond or rapport as "outsiders" who are not a part of the doctoral students' group. This can be seen in Irene's explicit identification of herself as an "outsider" ("I'm, I'm just an "outsider", no I'm a school teacher"), and in Elizabeth's show of empathy ("It gets like that though, when you're in this sort of community doesn't it?"), and subsequent identification as an "outsider" as well ("I don't know...I'm an undergraduate"). In doing so they both show consideration towards the feelings of each other. ${ }^{8}$

The contrast between the underlying conceptualisation of politeness in English and Japanese can also be seen in the following equivalent examples where chauffeurs are apologising to their employers for being late.

(3) (B is A's chauffeur)

A: Kimi, chotto osoi janai ka.

you a little late not $\mathrm{Q}$

(You're a little late aren't you?)

B: Osoku nari-mashita. Mooshiwake gozai-masen.

late become-Past(Pol) excuse have(Hon)-Neg(Pol)

(I am late. I am very sorry) (McClure, 2000: 7)

(4) (B is A's chauffeur)

A: Finally.

B: I'm very sorry, sir. The traffic was bad, and I should have left at four instead of five. It really is inexcusable, but I assure you that it will not happen again.

(McClure, 2000: 6)

In both English and Japanese, the chauffeurs apologise to the employers in a formal manner reflecting the power differential between these two interactants. 
In this sense, then, both examples involve showing respect towards the social position of others. There is, however, a marked difference in the composition of these apologies. One key difference is that the apology in the Japanese example is much shorter in comparison to the apology in the English example, as only in the latter does the chauffeur go into detail as to why he was late. This reflects a difference in the underlying conceptualisations of politeness. In English, the chauffeur shows consideration to the feelings of his employer, namely the employer's irritation that he is late. In contrast, the chauffeur in Japanese emphasises the higher social position of his employer through the 'polite forms' he utilises, and by not going into detail as to why he was late (based on the assumption that more junior employees should not give reasons, but rather should appeal to the benevolence of their superiors for any failures).

The way in which differences in underlying conceptualisations of politeness can give rise to intercultural misunderstandings is illustrated in the next example where an Australian student thanks his Japanese teacher by complimenting her. While this politeness strategy may be quite appropriate in English (that is, saying something like "I enjoyed your classes" to compliment a teacher), it sounds rather impolite in Japanese (the symbol * indicates that the utterance is inappropriate).

(5) *Sensei no jugyoo wa yokat-ta-desu.

Teacher of class Top good-Past-Pol

(Your classes were good) (Obana, 2000: 238)

In English, saying something like "Your classes were good" shows consideration towards the feelings of the teacher, thereby giving rise to politeness. In Japanese, however, it sounds impolite because one cannot directly praise the performance of those who are of higher status than oneself.

In the next example, a more appropriate way of thanking and complimenting one's teacher in Japanese is illustrated.

(6) Sensei, kono jugyoo o tot-te, taihen benkyoo ni nari-mashita.

Teacher this class Acc take-Conj very learning to become-Past(Pol)

(Sir, I really learned a lot from taking this class) (Haugh, 2003: 184)

By saying that he learned a lot from his teacher's class, and thereby implying that the teacher's performance was good, the student shows that he approves of his teacher and expresses his gratitude. Politeness arises in part because the student avoids taking a social position higher than his teacher (since he does not directly praise the teacher). In other words, he shows respect towards addressee's social position as a teacher. 
Differences in the English and Japanese conceptualisations of politeness are also reflected in examples of self-oriented politeness. Self-oriented politeness arises when one thinks someone is showing they do not think too highly of themselves. It can be represented in the following manner, where A is the speaker, B is the addressee, and ' $U$ ' is the speaker's utterance (including his or her manner of saying it).

Self-oriented Politeness arises when:

A says ' $U$ '

'U' shows A does not think highly of A

'U' shows A thinks the same or worse of A than what A should show A thinks of A

B thinks A does not think highly of A because of this

For example, if a colleague responds to my compliment about her new shoes by saying that they are nothing special (A says 'U'), she shows that she does not think her ability to choose nice shoes is particularly special ('U' shows A does not think highly of A). Politeness arises if I consequently think that my colleague does not think her ability to pick nice shoes is particularly special (B thinks A does not think highly of A because of this), and this is expected (' $U$ ' shows A thinks the same of $A$ as what A should show A thinks of A). In general, self-oriented politeness in Japanese involves showing modesty and restraint in relation to anything associated with one's individual character and (social) position, while in English it only involves showing modesty in regards to one's ability or skill. The scope encompassed by the English notion of politeness is thus more restricted than that covered by the Japanese notion.

For example, self-oriented politeness can arise in gift-giving exchanges in Japanese, as illustrated in example (7). In this conversation, Tanaka is offering a gift to Suzuki, but Suzuki refuses the gift a number of times before finally accepting it later on.

(7) Tanaka: Anoo, konna mono shitsurei-na-n-desu ga.

umm this kind of thing rude-Cop-Nomi-Pol but

(Well, this is not much to give but...)

Suzuki: Ara, nan des-oo.

oh what $\operatorname{Aux}(\mathrm{Pol})$

(Oh, what is it I wonder?)

Tanaka: Ano, hon no o-rei no shirushi ni...

well just of Hon-thanks of sign as 
(Well, it is just a token of my appreciation)

Suzuki: Maa, sonna koto o shi-te-itadai-te-wa komari-masu wa

oh that kind of thing Acc do-Te-receive(Hon)-Te-Cont trouble-Pol M

(Oh! You have done such a [kind] thing. I don't know what to say)

Tanaka: Ie, hontooni tsumaranai mono desu kara...

no really trivial thing $\mathrm{Cop}(\mathrm{Pol})$ so

(No, it is just a small thing so...)

Suzuki: Demo, konna koto shi-te-itadaku riyuu ga...

but this kind of thing do-Te-receive(Hon) reason Nom

(But [there is no] reason for you to do this)

Tanaka: Ie, hontooni kimochi dake desu kara, dooka o-osame-kudasai.

no really feeling only $\mathrm{Cop}(\mathrm{Pol})$ so somehow Hon-accept-please

(No, it is really only a token of my appreciation, so please accept it)

Suzuki: Soo desu ka. Ja, arigataku choodai-itashi-masu.

so Cop(Pol) Q well gratefully receive-Hon-Pol

Demo, hontooni warui-desu ne

but really bad-Pol $\mathrm{M}$

(Really? Well, I will gratefully receive it [then]. But I really feel bad)

(Aoki and Okamoto, 1988: 162-163)

Self-oriented politeness arises, for example, from Suzuki's comment Demo, konna koto shite itadaku riyuu ga ('But [there is no] reason for you to do this'), which implies that Suzuki thinks that she does not deserve to receive such a gift. In other words, Suzuki shows that she thinks her social position is not necessarily good enough to receive such a gift, thereby generating politeness. In English, however, it would be more common to thank the gift-giver with expressions such as 'How kind' or 'Oh, you shouldn't have', to show consideration towards the feelings of others (that is, a form of other-oriented politeness), rather than showing concern about one's own social position (that is, a form of self-oriented politeness). ${ }^{9}$

In another example of self-oriented politeness arising in this conversation, Tanaka says Hontoo ni tsumaranai mono desu kara ('it is just a small thing so [please accept it]'), which shows that she does not think so highly of the gift she is giving. This gives rise to politeness because by showing modesty in relation to the gift, Tanaka also shows modesty in regards to her own position (since her gift is assumed to be a part of her position in a Japanese context). This kind of utterance would not be appropriate in English, however, except in cases where the 
gift really was something quite trivial. If the gift were something quite nice, as it is in this example, then instead of being concerned about one's own social position (that is, a form of self-oriented politeness), it would be more common to express the hope or desire that the recipient will appreciate the gift, something like "I hope you like it" (that is, a form of other-oriented politeness). From these two instances of self-oriented politeness arising in this Japanese example, it is apparent that the scope of things about which one must be modest in English is smaller than that found in Japanese

In both these cases, it could be argued that other-oriented politeness also arises. For example, saying Demo, konna koto shite itadaku riyuu ga ('But [there is no] reason for you to do this'), also indicates that Suzuki is grateful towards Tanaka, which shows Suzuki thinks well of Tanaka. The point in these examples, however, is that self-oriented politeness is foregrounded, and thus is more salient. Other-oriented politeness arises, but it is only of background concern.

Self-oriented and other-oriented politeness are thus clearly inter-related. Showing what one thinks of oneself (self-oriented), naturally has implications for what one thinks of others (other-oriented); and what one thinks of others (other-oriented), has implications, as one might expect, for what one thinks of oneself (self-oriented). In other words, showing one does not think too highly of oneself (self-oriented politeness), may imply one thinks well of others (other-oriented politeness), and vice versa.

In this section it has been seen that while politeness in both English and Japanese involves showing one thinks well of others (other-oriented politeness) and showing one does not think too highly of oneself (self-oriented politeness), differences in the underlying conceptualisation of politeness give rise to different ways of expressing politeness. In the following section, the implications of this analysis for research about politeness are considered

\section{Conclusions and implications for further studies of politeness}

Politeness in both English and Japanese is crucially dependent on perceptions of what others show they think of us ("what B thinks A shows A thinks of B"), and themselves ("what B thinks A shows A thinks of A"). In particular, showing that one thinks well of others (other-oriented politeness), but not too highly of oneself (self-oriented politeness). In English, it involves showing consideration towards the feelings and position of others, and being well-mannered in one's demeanour. In Japanese, on the other hand, it is related to showing respect and consideration 
towards the individual character and social position of others, and showing modesty in regards to one's own character and position.

However, while differences between conceptualisations of politeness in English and Japanese have been emphasised in this paper, this is not to say that there are not also shared characteristics. One aspect common to both these notions is that politeness involves showing one thinks well of others (other-oriented politeness), and showing one does not think too highly of oneself (self-oriented politeness). Another partially shared aspect is that both English and Japanese politeness involve showing modesty in relation to self, and consideration towards others, although the dimensions encompassed by this consideration and modesty are somewhat different.

This analysis of the notions of politeness in English and Japanese also has a number of implications for further cross-cultural research on politeness. Firstly, it is difficult to maintain the assumption that politeness can be defined in the same way across different cultures. At an abstract level there are no doubt common elements, but if differences are not also acknowledged, then cross-cultural analysis becomes somewhat obscure. While no researchers would dispute the fact that politeness strategies and forms differ across languages and cultures, there remains considerable debate as to the source of these differences. In this paper, it has been proposed that at least some of these differences arise from the various ways in which politeness is conceptualised.

Secondly, there needs to be further work to clarify what elements are indeed common to politeness across cultures, and which elements are more culture-specific. In other words, there needs to be a movement beyond the universality versus cultural-specificity debate to a more inclusive approach that attempts to identify both the universal and more culture-specific elements of politeness across cultures.

The field of politeness research is diverse, reflecting the different aims of the many researchers working on politeness-related topics. While no one particular definition of politeness is ever likely to be consistent with that diverse range of research aims, this does not mean that the search for a more appropriate definition of politeness should be abandoned. In the end, it is most likely it will not be in the resulting definition, but rather in the search for that definition, where we will shall discover the most about this elusive notion. 


\section{Acknowledgements}

I would like to thank Yasuko Obana for all her helpful comments on the ideas in this paper, and for the useful points made by the two anonymous reviewers.

\section{References}

Alymursy, Ahmad and John Wilson

2001 Towards a definition of Egyptian complimenting. Multilingua 20: 133-154.

Aoki, Haruo and Shigeko Okamoto

1988 Rules for Conversation Rituals in Japanese. Tokyo: Taishukan.

Arundale, Robert

1993 Culture specific assumptions and the concept of face: a proposal toward a cultural universal for studying face management in using language. Paper presented at the International Pragmatics Conference, Kobe, Japan. (Revised 1997)

Braun, F. and K. Schubert

1988 When polite forms are impolite, or what politeness actually is. In F. Braun (ed.), Terms of Address. Problems of Patterns and Usage in Various Languages and Cultures. Berlin: Mouton de Gruyter, 45-64.

Brown, Penelope

2001 Politeness and language. In N. Smelser and P. Baltes (eds.), International Encyclopedia of the Social and Behavioural Sciences, Volume 17. Oxford: Elsevier Science, 11620-11624.

Brown, Penelope and Stephen Levinson

1987 Politeness. Some Universals in Language Usage. Cambridge: Cambridge University Press.

Chen, Rong

2001 Self-politeness: a proposal. Journal of Pragmatics 33, 87-106.

Eelen, Gino

1999 Politeness and ideology: a critical review. Pragmatics 9, 163-174.

Eelen, Gino

2001 A Critique of Politeness Theories. Manchester: St. Jerome.

Ehlich, Konrad

1992 On the historicity of politeness. In R. Watts, S. Ide, K. Ehlich (eds.),

Politeness in Language. Studies in its History, Theory and Practice.

Berlin: Mouton de Gruyter, 71-107. 
Fraser, Bruce

1990 Perspectives on politeness. Journal of Pragmatics 14, 219-236.

Fraser, Bruce and William Nolen

1981 The association of deference with linguistic form. International Journal of the Sociology of Language 27, 93-109.

Goffman, Erving

1967 Interaction Ritual. Essays on Face-to-face Behavior. New York: Pantheon Books.

Haugh, Michael

2003 Politeness Implicature in Japanese: A Metalinguistic Approach. Unpublished PhD dissertation, University of Queensland.

Haugh, Michael and Carl Hinze

2003 A metalinguistic approach to deconstructing the concepts of 'face' and 'politeness' in Chinese, English and Japanese. Journal of Pragmatics 35, 1581-1611.

Hill, Beverly, Sachiko Ide, Shoko Ikuta, Akiko Kawasaki and Tsunao Ogino 1986 Universals of linguistic politeness. Quantitative evidence from Japanese and American English. Journal of Pragmatics 10, 347-371.

Ide, Sachiko

1989 Formal forms and discernment: two neglected aspects of universals of linguistic politeness. Multilingua 8, 223-248.

1991 How and why do women speak more politely in Japanese? In S. Ide and N. McGloin (eds.), Aspects of Japanese Women's Language. Tokyo: Kurosio, 63-79.

1993 Preface: the search for integrated universals of linguistic politeness. Multilingua 12, 7-11.

2001 Kokusaika shakai no naka no keii hyoogen (Keiihyoogen in an internationalizing society). Nihongogaku 20, 4-13.

Ide, Sachiko, Beverly Hill, Yukiko Carnes, Tsunao Ogino and Akiko Kawasaki 1992 The concept of politeness: an empirical study of American English and Japanese. In R. Watts, S. Ide and K. Ehlich (eds.), Politeness in Language. Studies in its History, Theory and Practice. Berlin: Mouton de Gruyter, 281-297.

Ide, Sachiko and Megumi Yoshida

1999 Sociolinguistics: honorifics and gender differences. In N. Tsujimura (ed.), The Handbook of Japanese Linguistics. Oxford: Blackwell, 
444-480.

Ikuta, Shoko

1988 Strategies of requesting in Japanese conversational discourse. Unpublished PhD dissertation, Cornell University.

Janney, Richard and Horst Arndt

1993 Universality and relativity in cross-cultural politeness research: a historical perspective. Multilingua 12: 13-50.

Kamada, Masashi and Torataroo Komeyama (eds.)

1992 Daikangorin. Tokyo: Shuukan Shoten.

Klein, Lawrence

1994 Shaftesbury and the Culture of Politeness. Cambridge: Cambridge University Press.

Lakoff, Robin

1975 Language and Women's Place. New York: Harper \& Row.

Lau, D. C. (ed.)

1995 Er ya zhu zi suo yin; Xiao jing zhu zi suo yin (Concordances to the Erya, Xiaojing). Hong Kong: Commercial Press.

Leech, Geoffrey

1983 Principles of Pragmatics. London: Longman

Leech, Geoffrey

1999 Politeness and pragmatics: a reconsideration. Paper presented at the JACET conference, Tokyo, Japan.

Lee-Wong, Song Mei

2002 Contextualising intercultural communication and sociopragmatic choices. Multilingua 21: 79-99.

Legge, James

1891 The Texts of Taoism. Part I. The Tao Te King. The Writings of Kwang-Tze. Oxford: Clarendon.

Marquez-Reiter, Rosina

2000 Linguistic Politeness in Britain and Uruguay. A Contrastive Study

of Requests and Apologies. Amsterdam: John Benjamins.

Matsumoto, Yoshiko

1989 Politeness and conversational universals - observations from Japanese. Multilingua 8: 207-221.

McClure, William

2000 Using Japanese. Cambridge: Cambridge University Press. 
Meier, A. J.

1995a Passages of politeness. Journal of Pragmatics 24, 381-392.

1995b Defining politeness: Universality in appropriateness. Language Sciences 17, 345-356.

Mills, Sara

2003 Gender and Politeness. Cambridge: Cambridge University Press.

Nwoye, Onuigobo

1989 Linguistic politeness in Igbo. Multilingua 8, 259-275.

Obana, Yasuko and Takako Tomoda

1994 The sociological significance of 'politeness' in English and Japanese languages - report from a pilot study. Japanese Studies Bulletin 14, 37-49.

1996 Language diplomacy and Japanese politeness. New Zealand Journal of East Asian Studies 4: 64-75.

Obana, Yasuko

2000 Understanding Japanese. A Handbook for Learners and Teachers Tokyo: Kurosio.

Pearsall, Judy (ed.)

1998 The New Oxford Dictionary of English. Oxford: Clarendon Press.

Shinmura, Izuru (ed.)

1991. Koojien (4th edition). Tokyo: Iwanami Shoten.

Sifianou, Maria

1992 Politeness Phenomena in England and Greece. Oxford: Clarendon Press.

Simpson, J. A. and E. S. C. Weiner (eds.)

1989 The Oxford English Dictionary. Oxford: Clarendon Press.

Spencer-Oatey, Helen

2000 Rapport management: a framework for analysis. In $\mathrm{H}$. Spencer-Oatey (ed.), Culturally Speaking. Managing Rapport through Talk across Cultures. London: Continuum, 11-46.

Terkourafi, Marina

2001 Politeness in Cypriot Greek: A Frame-based Approach. Unpublished $\mathrm{PhD}$ dissertation, Cambridge University.

Usami, Mayumi

2001 Danwa no poraitonesu - poraitonesu no danwa riron koosoo

(Discourse politeness: Discourse theory of politeness - a preliminary 
framework. In M. Kai (ed.), Danwa no Poraitonesu (Discourse Politeness). Tokyo: The National Language Research Institute, 9-58. 2002 Discourse Politeness in Japanese Conversation: Some Implications for a Universal Theory of Politeness. Tokyo: Hituzi Syobo.

Watts, Richard

1989 Relevance and relational work: linguistic politeness as politic behaviour. Multilingua 8: 131-166.

1992 Linguistic politeness and politic verbal behaviour: reconsidering claims for universality. In R. Watts, S. Ide and K. Ehlich (eds.), Politeness in Language. Studies in its History, Theory and Practice. Berlin: Mouton de Gruyter, 43-69.

1999 Language and politeness in early eighteenth century Britain. Pragmatics 9, 5-20.

2002 Politeness, politic behaviour and power: A discursive approach to politeness phenomena. Paper presented at the Politeness and Power Conference, Loughborough University, United Kingdom.

Watts, Richard, Sachiko Ide and Konrad Ehlich

1992 Introduction. In R. Watts, S. Ide and K. Ehlich (eds.), Politeness in Language. Studies in its History, Theory and Practice. Berlin: Mouton de Gruyter, 1-17.

Wildeblood, Joan and Peter Brinson

1965 The Polite World. A Guide to English Manners and Deportment from the Thirteenth to the Nineteenth Century. London: Oxford University Press.

\footnotetext{
${ }^{1}$ Although Watts $(1992,1999)$ argues that in spite of these changes, politeness is still sometimes evaluated negatively in Britain due to a lingering perception that it remains a kind of social class marker.

${ }^{2}$ The abbreviations used in the morphological gloss are based on those used by Obana (2000: 27): Acc = accusative; Aux = auxilliary; Conj = conjuncation; Cont = contrastive marker; Cop = copula; Hon = honorific marker; Imp = imperative form; $\mathrm{M}=\operatorname{mood}$ marker; Neg = negation; Nom = nominative; Past = past tense; Pol = polite form; $\mathrm{Q}$ = question marker; Quot = quotation marker; $\mathrm{Te}=$ 'te-form'; Top = topic marker.

${ }^{3}$ All translations from Japanese into English are by the author.

${ }^{4}$ Mibun is defined as 'the order of the hierarchial rank of people that constitutes society' (Shinmura, 1991: 2470), while chii is defined as one's 'rank' (kurai) or 'position relative to others' (tachiba) (ibid: 1638).

${ }^{5}$ These notions build upon Goffman's distinction between 'deference' and 'demeanour' (see Arundale (1993) and Chen (2001) for further discussion).
} 
${ }^{6}$ Politeness may be conceptualised both as a 'form' (that is, linguistic forms such as honorifics in Japanese, or expressions like 'Would you mind...?' or please, thank you and so on in English, which are regarded as 'polite'), or as an 'effect' (that is, where one thinks someone else is being polite) (cf. Ikuta, 1988: 1-2). However, an addressee may come to believe that a speaker is being polite for a variety of reasons other than the use of 'polite forms', and 'polite forms' do not necessarily always give rise to 'polite effects', so the relationship between 'polite forms' and 'polite effects' is somewhat complex.

${ }^{7}$ This conversation was transcribed by the researcher as part of an on-going project comparing politeness in various languages. The names are changed from those of the original interactants.

${ }^{8}$ As pointed out by one of the reviewers, this example could also be regarded as an example of a positive politeness strategy, to 'assert common ground' (Brown and Levinson, 1987:

123-124), which illustrates the usefulness of Brown and Levinson's framework for analysing examples of politeness in English. However, it is often less effective in analysing politeness in Japanese. While Brown and Levinson classify honorifics as a type of negative politeness strategy (ibid: 178-181), the politeness arising in example (1) cannot be regarded as negative politeness, since this politeness is generated from the speaker's show of respect towards the other's position, rather than from avoidance of imposition.

${ }^{9}$ Expressions such as 'How kind [you are]' and 'Oh, you shouldn't have' are primarily focused on others, and so are examples of other-oriented politeness. This contrasts with the Japanese expression in example (7) where the verb of receiving (itadaku) is a humble form, and thus is an example of self-oriented politeness (since humble forms can only generate politeness when used in reference to one's own actions or state). 